\title{
Perinatal outcomes of frequent attendance in midwifery care in the Netherlands: a retrospective cohort study
}

Janneke T. Gitsels-van der Wal ${ }^{1 *} \mathbb{D}$, Lisanne A. Gitsels ${ }^{2,3}$, Angelo Hooker ${ }^{4,5}$, Paula Scholing ${ }^{1}$, Linda Martin ${ }^{1}$ and Esther I. Feijen-de Jong ${ }^{1,6}$

\begin{abstract}
Background: Over the last decade, a trend towards high utilisation of primary maternity care was observed in high-income countries. There is limited research with contradictory results regarding frequent attendance (FA) and perinatal outcomes in midwifery care. Therefore, this study examined possible associations between FA in midwifery care and obstetric interventions and perinatal outcomes.

Methods: A retrospective cohort study was performed in a medium-sized midwifery-led care practice in an urban region in the Netherlands. Frequent attenders (FAs) were categorised using the Kotelchuck-Index Revised. Regression analyses were executed to examine the relationship between FAs and perinatal outcomes, stratified by antenatal referral to an obstetrician. Main outcomes of interest were Apgar score $\leq 7$ and perinatal death, birth weight, mode of delivery, haemorrhage, place of birth, transfer during labour, and a requirement for pain relief.

Results: The study included 1015 women, 239 (24\%) FAs and 776 (76\%) non-FAs, 538 (53\%) were not referred and 447 (47\%) were referred to an obstetrician. In the non-referred group, FA was significantly associated with a requirement for pain relief (OR 1.98, 95\% Cl 1.24-3.17) and duration of dilatation (OR 1.20, 95\% Cl 1.04-1.38). In the referred group, FA was significantly associated with induction of labour (OR 1.86, 95\% Cl 1.17-2.95), ruptured perineum (OR 0.50, 95\% Cl 0.27-0.95) and episiotomy (OR 0.48, 95\% Cl 0.24-0.95). In the non-referred and the referred group, FA was not associated with the other obstetric and neonatal outcomes. Due to small numbers, we could not measure possible associations of FA with an Apgar score $\leq 7$ and perinatal death.

Conclusion: In our study, perinatal outcomes differed by FA and antenatal referral to an obstetrician. In the nonreferred group, FA was significantly associated with medical pain relief and duration of dilatation. In the referred group, FA was significantly associated with induction of labour, ruptured perineum, and episiotomy. Further research with a larger study population is needed to look for a possible association between FA and primary adverse birth outcomes such as perinatal mortality.
\end{abstract}

Keywords: Midwifery, Obstetric delivery, Perinatal outcomes, population health, Frequent attendance, Pain relief, Induced labour, Healthcare utilisation, Patient acceptance of health care, Low-risk women

\footnotetext{
* Correspondence: jt.vanderwal@vumc.nl; Janneke@hllp.nl

'Amsterdam UMC, Vrije Universiteit Amsterdam, Midwifery Science, AVAG,

Amsterdam Public Health research institute, Van der Boechorststraat 7, 1081

HV Amsterdam, The Netherlands

Full list of author information is available at the end of the article
}

(c) The Author(s). 2020 Open Access This article is licensed under a Creative Commons Attribution 4.0 International License, which permits use, sharing, adaptation, distribution and reproduction in any medium or format, as long as you give appropriate credit to the original author(s) and the source, provide a link to the Creative Commons licence, and indicate if changes were made. The images or other third party material in this article are included in the article's Creative Commons licence, unless indicated otherwise in a credit line to the material. If material is not included in the article's Creative Commons licence and your intended use is not permitted by statutory regulation or exceeds the permitted use, you will need to obtain permission directly from the copyright holder. To view a copy of this licence, visit http://creativecommons.org/licenses/by/4.0/ The Creative Commons Public Domain Dedication waiver (http://creativecommons.org/publicdomain/zero/1.0/) applies to the data made available in this article, unless otherwise stated in a credit line to the data. 


\section{Background}

Frequent attendance (FA) has become a growing health problem and a central issue in primary health care systems [1-3]. FA leads to a higher workload and pressure on the healthcare system and does not improve health outcomes per se. FA is defined as the top $10 \%$ of the total number of visits during 1 year in practice, and its prevalence has increased from 2 to $20 \%$ in the last two decades [2, 4-7]. Factors contributing to higher rates of FA are age, educational level, ethnicity, living area, body mass index (BMI), smoking and alcohol consumption [1, 2, 8-15]. Despite a fivefold increase in costly hospital referrals, frequent attenders (FAs) showed repeatedly multi-morbid health disorders such as psychiatric illness, emotional distress, social difficulties and reduced self-reported quality of life $[1,2,5,16-18]$. The trend towards increased FA has also been observed in maternity health care [19-23]. Guidelines about the appropriate number of antenatal visits among low-risk women differ worldwide, due to diverse prenatal health care systems, ranging between eight to 14 visits [20, 24-26]. During the last decade, FA in the Netherlands increased from 13 to $23 \%$ [23]. Previous studies showed that FA in midwifery care is mainly associated with worries and vague complaints; single marital status, assisted conception, sexual violence and psychosocial problems are considered important underlying factors, which increase anxious feelings and lead to more prenatal visits [23, 27-32].

The recommended number of prenatal visits aims to establish the best possible perinatal outcomes [25]. Inadequate prenatal care, defined as a significantly lower number of visits than recommended, is associated with adverse maternal and perinatal outcomes [19, 33, 34]. However, little research has been conducted regarding the relationship between FA, obstetric interventions and perinatal outcomes in midwifery care. An American study reported an increased number of obstetric interventions (induction of labour and caesarean section) among FAs with a low-risk status for obstetric complications compared to similar low-risk non-frequent attenders (non-FAs) [27]. However, no significant differences were reported in Apgar scores or small for gestational age [27]. In contrast, a Dutch study reported no associations between FA and obstetric interventions but reported an increased risk for preterm birth, low Apgar scores, low birth weight and perinatal mortality among FA low-risk women [35]. Few studies examined the relationship between FA and perinatal outcomes among high-risk women in obstetric-led care. A prospective cohort study among women with gestational diabetes and type 2 diabetes examined a possible association between the number of prenatal visits and perinatal outcomes; results showed improved neonatal outcomes of FAs [36].

In a previous study, we assessed the prevalence of FA in Dutch midwifery care and its underlying reasons [23]. Drawing on this work, the current study aimed to examine possible associations between FA in Dutch midwifery care and perinatal outcomes (e.g. obstetric interventions and neonatal outcomes). As antenatal referral to an obstetrician was found to be an effect modifier of prenatal healthcare utilisation in previous studies [19, 23], we compared the outcomes of women with FA to those with the recommended number of visits and stratified by referral.

\section{Methods}

\section{Study design}

The current retrospective cohort study was performed in a midwifery practice with an average of 750 low-risk pregnant women per year and situated in an urban region close to Amsterdam, the Netherlands. Women were recruited from January 2015 to January 2017. The Medical Ethics Committee of the Amsterdam University Medical Center approved the study (ref. 2018.019).

\section{Participants}

All women registered for prenatal care at this midwifery practice approved the use of their anonymous data for research to improve the quality of prenatal care and were eligible for inclusion. Women were excluded if they had a miscarriage, ectopic pregnancy or were referred to an obstetrician in the first trimester. Women who only received postnatal care or who were referred to another practice before giving birth were also excluded. The remaining cohort was included and grouped based on the level of health care utilisation using the Kotelchuck Index-Revised (KI-R).

The KI-R is a validated index based on the guidelines by Royal Dutch Organisation of Midwives and calculated by the number of face-to-face prenatal visits with a midwife, gestation and onset of care (Additional file 1: Appendix 1) [19, 37]. Women were categorized according to health care utilisation; inadequate (KI-R of $<50 \%$ ), intermediate (50-79\%), adequate (KI-R of $80-109 \%)$, and adequate plus (KI-R of $>=110 \%$ ). Women with inadequate or intermediate use of care were excluded in the current analysis. The final cohort consisted of women with adequate utilisation of care (KI-R of $80-$ $109 \%$ ), classified as non-FAs and women with adequate plus the utilisation of care (KI-R of $>=110 \%$ ), classified as FAs.

\section{Dutch maternity care context}

In the Dutch maternity care system, low-risk women are guided in midwifery care in the community, and high- 
risk women are guided in obstetric care at the hospital; midwives refer low-risk women to obstetricians in case of (suspected) complications. Guided by midwives, lowrisk women have the option to give birth at home or in a birth centre (outside or in a hospital). Induction of labour is only possible in obstetric-led care.

\section{Data collection and perinatal outcomes}

Anonymised data were obtained from the digital maternity database [23]. These standardised data included level of health care utilisation, perinatal and neonatal outcomes, and sociodemographic and medical characteristics. Outcomes of primary concern to health professionals are Apgar Score ( $<8$ after 5 min of delivery) and perinatal death. Other outcomes of interest in this study were birth weight $(<10$ th percentile for gestational age), mode of delivery (spontaneous, vaginal assisted, Caesarean section), perineum status (non-ruptured, ruptured, or episiotomy), haemorrhage $(<1000 \mathrm{ml})$, place of birth (home, birth centre or hospital), gestational age at onset of labour (in weeks), transfer during labour (e.g. because of insufficient progress of dilatation, request for pain relief or signs of fetal distress), pain relief (morphine or epidural anaesthesia), duration of dilatation (in hours), and duration of expulsion (in minutes).

The sociodemographic and medical information included: age (in years), education (low: primary school and uncompleted vocational training / intermediate: secondary school and completed vocational training / high: college or university) [23], ethnicity (Dutch/western non-Dutch/non-western non-Dutch), marital status (partner yes/no), occupation (yes/no), deprivation based on postal code (no/yes) [38], parity (nulliparous/multiparous), mode of conception (unassisted/assisted), psychosocial problems (no/yes in the past/yes at present), sexual violence (no/yes), smoking (no/yes), alcohol consumption (no/yes), drugs addiction (no/yes), body mass index (BMI, normal weight/overweight/obese) [39], and antenatal referral to obstetrician (no/yes). Psychosocial problems were defined as 'the broad spectrum of all complaints which are not strictly medical or somatic and affect the patient's functioning in daily life; for example, stress, sleep disorder, relationship problems, financial problems, housing problems and adjustment problems [40].

\section{Analyses}

Descriptive statistics were obtained to summarise characteristics of the study population by FA and referral. For continuous variables, if normally distributed, the means and standard deviations were obtained; otherwise, the median and interquartile range were obtained. For categorical variables, frequencies and prevalences were obtained.
Regression analyses were executed to estimate the associations of FA with perinatal outcomes in nonreferred and referred participants. Logistic models were conducted for binary outcomes, nominal logit models were conducted for categorical outcomes, and linear models were conducted for continuous outcomes. No models were conducted for induction of labour among non-referred as this would only happen in obstetric led care, for the same reason no models were conducted for the place of birth and transfer during labour among the referred group as this would only happen in midwifery care.

Binary variables were excluded from the regression analyses if a category was less than $5 \%$ prevalent. Categorical variables were regrouped if a category was less than $5 \%$ prevalent. Age was centred around the mean to have a meaningful baseline. The final adjusted models included the exposure and all supporting variables that were significant $(p<.05)$ using backward elimination. The models' assumptions and performances were assessed. In case variables were not normally distributed, they were log-transformed to comply with the linear model assumptions; the model's coefficients were exponentiated, resulting in odds ratios. All analyses were performed by two researchers independently from each other in SPSS (version 24).

\section{Results}

A total of 1015 women were included in the current analysis (Fig. 1). Table 1 shows the characteristics of the study population. On average, women were aged 29 years at conception. Roughly half of the women were multiparous (53\%). Approximately $48 \%$ of the women were Dutch, $8 \%$ were Western non-Dutch, and $44 \%$ were non-Western non-Dutch. One in five lived in a deprived area. Based on the utilisation of prenatal care, 239 (24\%) were FAs (KI-R $>109 \%)$ and $776(76 \%)$ were non-FAs (KI-R of $80-109 \%)$. Of the women included, 528 (53\%) were not referred to an obstetrician during pregnancy, and 477 (47\%) were referred (Table 2). The main reasons for referral were glucose intolerance $(28 \%)$, pregnancyinduced hypertension (15\%), and a previous C-section (10\%) (Table 3).

\section{FAs versus non-FAs}

FA was associated with (former) psychosocial problems (15\% FA versus 7\% non-FA), a history of sexual violence ( $21 \%$ versus $10 \%)$, an assisted start of conception ( $8 \%$ versus $4 \%$ ), smoking (32\% versus $21 \%$ ) and alcohol consumption ( $8 \%$ versus $3 \%$ ) (Table 1$)$.

Regarding perinatal outcomes (Table 4), FA was associated with place of birth; FAs had more hospital deliveries than non-FAs (80\% FA versus $72 \%$ non-FA) and less home and birth centre deliveries (3 and 17\% versus 7 


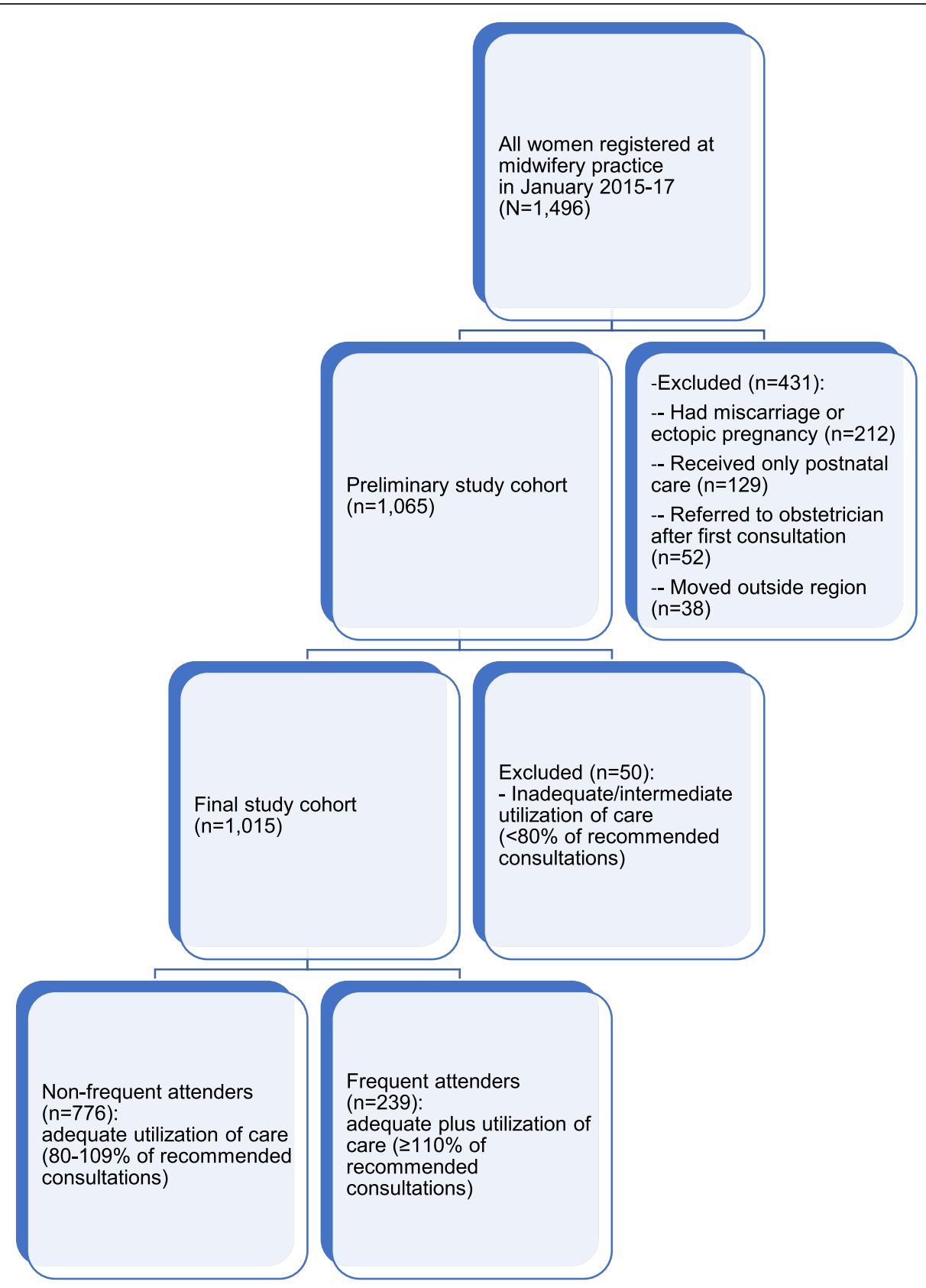

Fig. 1 Flowchart of the eligible study population

and $21 \%$, respectively). Furthermore, FA was associated with induction of labour ( $42 \%$ versus $27 \%$ non-FA) and with medical pain relief ( $52 \%$ versus $38 \%$ non-FA). We found no significant differences in other outcomes.

\section{Non-referred pregnant women}

In the non-referred group $(N=538), \mathrm{FA}$ was associated with a history of sexual violence (16\% FA versus 9\% non-FA), smoking (30\% versus 19\%) and alcohol consumption ( $8 \%$ versus $3 \%$ ) (Table 2 ).
Regarding perinatal outcomes (Table 5), FA was associated with place of birth; FAs had more hospital deliveries than non-FAs (59\% FA versus 52\% nonFA) and fewer home deliveries (5\% versus $12 \%$ ). FA was also associated with medical pain relief (42\% FA versus $26 \%$ non-FA), dilatation time (8 versus $6 \mathrm{~h}$ ), transfer during labour (56\% versus $49 \%$ ), episiotomy ( $24 \%$ versus $16 \%$ ), Apgar score $\leq 7$ (5\% versus $2 \%$ ), and birth weight under the 10 th percentile $(6 \%$ versus $11 \%)$. 
Table 1 Characteristics of frequent attenders and non-frequent attenders ( $N=1015)$

\begin{tabular}{|c|c|c|c|c|}
\hline & $\begin{array}{l}\text { Complete study } \\
\text { population } N=1015\end{array}$ & $\begin{array}{l}\text { Frequent attender } \\
N=239(23.5 \%)\end{array}$ & $\begin{array}{l}\text { Non-frequent attender } \\
N=776(76.5 \%)\end{array}$ & $\boldsymbol{P}$ value \\
\hline \multicolumn{5}{|l|}{ Consultations } \\
\hline Face-to-face Mean (sd) & $11(4.2)$ & $14(4.1)$ & $10(3.7)$ & $<.01$ \\
\hline $\begin{array}{l}\text { Age in years } \\
\text { mean (sd) }\end{array}$ & $29.3(4.9)$ & $28.8(5.1)$ & $29.4(4.8)$ & .24 \\
\hline Level of Education* & & & & .77 \\
\hline Low & $119(12.1)$ & $26(11.3)$ & $93(12.4)$ & \\
\hline Medium & $459(46.7)$ & $112(48.7)$ & $347(46.1)$ & \\
\hline High & $405(41.2)$ & $92(40)$ & $313(41.6)$ & \\
\hline Ethnic Background* & & & & .08 \\
\hline Dutch & $483(47.6)$ & $128(53.6)$ & $355(45.8)$ & \\
\hline Western Non-Dutch & $82(8.1)$ & $14(5.9)$ & $68(8.8)$ & \\
\hline Non-Western Non-Dutch & $449(44.3)$ & $97(40.6)$ & $352(45.4)$ & \\
\hline Married/partner & $990(97.5)$ & $230(96.2)$ & $760(97.9)$ & .14 \\
\hline Employed* & $696(69.1)$ & $165(69.3)$ & $531(69.1)$ & \\
\hline Deprived area & $210(20.7)$ & $42(17.6)$ & $168(21.6)$ & .17 \\
\hline Parity & & & & .24 \\
\hline Nulliparous & $480(47.3)$ & $121(50.6)$ & $359(46.3)$ & \\
\hline Multiparous & $535(52.7)$ & $118(49.4)$ & $417(53.7$ & \\
\hline Start of conception* & & & & .03 \\
\hline Spontaneous & $953(94.7)$ & $218(92)$ & 735 (95.6) & \\
\hline Assisted & $53(5.3)$ & $19(8)$ & $34(4.4)$ & \\
\hline Psychosocial problems* & & & & $<.01$ \\
\hline Yes in the past & $202(20)$ & $58(24.3))$ & $144(18.6)$ & \\
\hline Yes at present & $87(8.6)$ & 35 (14.6) & $52(6.7)$ & \\
\hline Sexual violence* & $127(12.5)$ & 49 (20.6) & $78(10.1)$ & $<.01$ \\
\hline Smoking* & $235(23.2)$ & $76(31.8)$ & $159(20.5)$ & $<.01$ \\
\hline Alcohol use* & $42(4.1)$ & $18(7.5)$ & $24(3.1)$ & $<.01$ \\
\hline Drugs addiction* & $22(2.2)$ & $9(3.8)$ & $13(1.7)$ & .05 \\
\hline BMI* & & & & .17 \\
\hline Overweight & $248(24.5)$ & $69(28.9)$ & $179(23.2)$ & \\
\hline Obese & 133 (13.2) & $27(11.3)$ & $106(13.7)$ & \\
\hline
\end{tabular}

*sample size varies due to missing data; valid percentages are shown **standard deviation

\section{Referred pregnant women}

Among the referred group $(N=477)$, FA was associated with a Dutch background (56\% FA versus $42 \%$ non-FA), living in a deprived area (17\% versus $27 \%$ ), psychosocial problems (25\% versus 19\%), a history of sexual violence ( $24 \%$ versus $12 \%$ ), smoking (33\% versus $22 \%$ ), alcohol consumption ( $8 \%$ versus $3 \%)$, and drug addiction $(6 \%$ versus $2 \%$ ) (Table 2 ).

Regarding perinatal outcomes (Table 5), FA was significantly associated with induction of labour (73\% FA versus 59\% non-FA), episiotomy (19 and 28\%) or ruptured perineum (21 and 28\%), C-section (27 and 24\%), vaginal assisted birth (7 and 11\%), medical pain relief
(60\% versus $52 \%)$ and haemorrhage (5\% versus $10 \%)$. FAs had less often a baby with an Apgar Score $\leq 7$ (2\% FA versus $4 \%$ non-FA), and perinatal death ( $0 \%$ versus $2 \%)$. Main reasons for transfer during labour were a request for pain relief (28\%), insufficient progress of dilatation (25\%) and meconium-stained fluid (14\%).

\section{Regression analysis of estimation of FA on obstetric and neonatal outcomes}

The results of the regression analyses, unadjusted and adjusted for medical and sociodemographic factors, are presented in Table 6. Mode of delivery was made binary due to the low prevalence of vaginal assisted birth which 
Table 2 Characteristics of non-frequent and frequent attenders divided by referrals $(\mathrm{N}=1015)$

\begin{tabular}{|c|c|c|c|c|c|c|}
\hline & $\begin{array}{l}\text { Non-referred } \\
\text { frequent attender } \\
N=107(10.5 \%)\end{array}$ & $\begin{array}{l}\text { Non-referred } \\
\text { non-frequent attender } \\
N=431(42.5 \%)\end{array}$ & & $\begin{array}{l}\text { Referred frequent } \\
\text { attender } \\
N=132(13.0 \%)\end{array}$ & $\begin{array}{l}\text { Referred non- } \\
\text { frequent attender } \\
N=345(34.0 \%)\end{array}$ & \\
\hline Consultations & & & $<.01$ & & & $<.01$ \\
\hline $\begin{array}{l}\text { Face-to-face } \\
\text { Mean (sd) }\end{array}$ & $15.8(3.3)$ & $12.0(2.5)$ & & $12.6(4.1)$ & $7.7(3.6)$ & \\
\hline Age in years & & & .26 & & & .12 \\
\hline mean (sd) & $28.2(5.0)$ & $28.8(4.7)$ & & $29.4(5.1)$ & $30.2(4.9)$ & \\
\hline Level of Education* & & & .56 & & & .81 \\
\hline Low & $8(7.7)$ & $48(11.5)$ & & $18(14.3)$ & $45(13.4)$ & \\
\hline Medium & $54(51.9)$ & $194(46.4)$ & & $58(46.0)$ & $153(45.7)$ & \\
\hline High & $42(40.4)$ & $176(42.1)$ & & $50(39.7)$ & $137(40.9)$ & \\
\hline Ethnic Background* & & & .69 & & & .03 \\
\hline Dutch & $54(50.5)$ & $209(48.5)$ & & $74(56.1)$ & $146(42.4)$ & \\
\hline Western Non-Dutch & $9(8.4)$ & $48(11.1)$ & & $5(3.8)$ & $20(5.8)$ & \\
\hline Non-Western Non-Dutch & $44(41.1)$ & $174(40.4)$ & & $53(40.2)$ & $178(51.7)$ & \\
\hline Married/partner & $103(96.3)$ & 419 (97.2) & .62 & $127(96.2)$ & 341 (98.8) & .06 \\
\hline Employed* & $74(69.8)$ & $294(68.7)$ & .80 & $91(68.9)$ & $237(69.5)$ & .90 \\
\hline Deprived area & 19 (17.8) & 76 (17.6) & .98 & $23(17.4)$ & $92(26.7)$ & .04 \\
\hline Parity & & & .46 & & & .29 \\
\hline Nulliparous & $56(52.3)$ & $206(47.8)$ & & $65(49.2)$ & $153(44.3)$ & \\
\hline Multiparous & $51(47.7)$ & $225(52.2)$ & & $67(50.8)$ & $192(55.7)$ & \\
\hline Start of conception* & & & .99 & & & .16 \\
\hline Spontaneous & $102(96.2)$ & $410(96.2)$ & & $116(88.5)$ & $325(94.8)$ & \\
\hline Assisted & $4(3.8)$ & $16(3.8)$ & & $15(11.5)$ & $18(5.2)$ & \\
\hline Psychosocial problems* & & & .51 & & & $<.01$ \\
\hline Yes in the past & $25(23.4)$ & $80(18.7)$ & & $33(25.0)$ & $64(18.6)$ & \\
\hline Yes at present & $8(7.5)$ & $27(6.3)$ & & $27(20.5)$ & $25(7.2)$ & \\
\hline Sexual violence* & $17(16.0)$ & $37(8.6)$ & .03 & $32(24.2)$ & $41(11.9)$ & $<.01$ \\
\hline Smoking* & $32(29.9)$ & $82(19.1)$ & .01 & $44(33.3)$ & $77(22.4)$ & .02 \\
\hline Alcohol use* & $8(7.5)$ & $14(3.3)$ & .05 & $10(7.6)$ & $10(2.9)$ & .02 \\
\hline Drugs addiction* & $1(0.9)$ & $8(1.9)$ & .51 & $8(6.1)$ & $5(1.5)$ & .01 \\
\hline BMI* & & & .67 & & & .21 \\
\hline Overweight & $23(21.5)$ & $91(21.3)$ & & $46(34.8)$ & 88 (25.6) & \\
\hline Obese & $5(4.7)$ & $39(9.1)$ & & $22(16.7)$ & $67(19.5)$ & \\
\hline
\end{tabular}

*sample size varies due to missing data; valid percentages are shown

** standard deviation; ${ }^{*} p \leq .05 ; \sim p \leq .01$

was therefore grouped with C-section as 'assisted birth'. Duration of dilatation and expulsion were non-normally distributed and thus, log-transformed to comply with the linear model assumptions. No regression models were conducted for perinatal death and low Apgar score due to their low prevalence. Furthermore, no regression models were conducted for gestational age at onset of labour as there was minor variation between the groups of women and they were not clinically relevant. Only the adjusted effects that were significantly associated or of substantial size (more than half as likely) are discussed.

In the non-referred group, FA compared to nonFA was significantly associated with medical pain relief $(\mathrm{OR}=1.98 \quad(1.24-3.17))$ and longer dilatation time $(\mathrm{OR}=1.20(1.04-1.38))$. There were no significant differences by health care utilisation in low birth weight, place of birth, transfer during labour, mode of delivery, haemorrhage, perineum, and duration of expulsion. 
Table 3 Reasons for antenatal referral among the referred population $(\mathrm{N}=477)$

\begin{tabular}{ll}
\hline Reasons & $\mathrm{N}(\%)$ \\
\hline Glucose intolerance & $132(27.7)$ \\
Pregnancy-induced hypertension & $70(14.7)$ \\
Previous C-section & $47(9.9)$ \\
Post terme ( $\geq 42$ weeks)/request for induction & $30(6.3)$ \\
Breech or other malpresentation & $27(5.7)$ \\
Decreased fetal movements & $22(4.6)$ \\
Intercurrent disease & $17(3.6)$ \\
Small for gestational age & $16(3.4)$ \\
Premature birth & $15(3.1)$ \\
Congenital anomaly & $10(2.1)$ \\
Large for gestational age & $11(2.3)$ \\
Anaemia & $11(2.3)$ \\
Previous small for gestational age & $9(1.9)$ \\
Hydramnion & $6(1.3)$ \\
Placenta problems & $5(1)$ \\
Uterus anomaly/cyst/myomas & $5(1)$ \\
Stillbirth & $4(.8)$ \\
Hyperemesis & $2(.4)$ \\
Fetal distress & $2(.4)$ \\
Blood loss & $2(.4)$ \\
Otwin pregnancy & $1(.2)$ \\
defects, rheumatism, gastric bypass, pelvic pain & $33(6.9)$ \\
\hline valid percentages are shown & \\
\hline
\end{tabular}

In the referred group, FA compared to non-FA was significantly associated with induction of labour $(\mathrm{OR}=$ $1.86(1.17-2.95))$, ruptured perineum $(\mathrm{OR}=0.50(0.27$ $0.95)$ ) and episiotomy $(\mathrm{OR}=0.48(0.24-0.95))$. FA was not significantly associated with haemorrhage, medical pain relief, mode of delivery, birth weight, and durations of dilatation and expulsion.

\section{Discussion}

To our best knowledge, our study is the first to examine the associations between FA perinatal outcomes and FA in midwifery-led care. Nearly a quarter $(24 \%)$ of the included women in our study were considered FAs and received more prenatal visits than the national recommendations. In the group of women who were not referred to an obstetrician during the pregnancy, FA was significantly associated with medical pain relief and duration of dilatation. In the referred group, FA was significantly associated with induction of labour, ruptured perineum and episiotomy.

\section{Strengths and limitations}

Our study addressed the non-consistent results of the current literature on the effect of FA on perinatal outcomes
Table 4 Perinatal outcomes of frequent attenders and nonfrequent $(N=1015)$

\begin{tabular}{|c|c|c|c|c|}
\hline & $\begin{array}{l}\text { Complete study } \\
\text { population } \\
N=1015 \\
(100 \%)\end{array}$ & $\begin{array}{l}\text { Frequent } \\
\text { attender } \\
N=219 \\
(23.5 \%)\end{array}$ & $\begin{array}{l}\text { Non-frequent } \\
\text { attender } \\
N=776 \\
(76.5 \%)\end{array}$ & $\boldsymbol{P}$ value \\
\hline $\begin{array}{l}\text { Apgar Score } \\
\text { after } 5 \mathrm{~min}^{*}\end{array}$ & & & & .93 \\
\hline$<8$ & $29(2.9)$ & $7(3)$ & $22(2.8)$ & \\
\hline Perinatal death & $11(1.1)$ & $1(.4)$ & $10(1.3)$ & .26 \\
\hline $\begin{array}{l}\text { Birthweight } \\
\text { (in percentiles)* }\end{array}$ & & & & .24 \\
\hline$P<10$ & $101(10.1)$ & $19(8.1)$ & $82(10.7)$ & \\
\hline Mode of delivery * & & & & .24 \\
\hline Spontaneous & $764(75.5)$ & $174(73.1)$ & $590(76.2)$ & \\
\hline $\begin{array}{l}\text { Vaginal assisted } \\
\text { birth }\end{array}$ & $103(10.2)$ & $22(9.2)$ & $81(10.5)$ & \\
\hline Caesarean section & $145(14.3)$ & $42(17.6)$ & $103(13.3)$ & \\
\hline Perineum* & & & & .28 \\
\hline Not ruptured & $442(50.7)$ & $109(54.8)$ & $333(49.5)$ & \\
\hline Ruptured & $248(28.4)$ & $48(24.1)$ & $200(29.7)$ & \\
\hline Episiotomy & $182(20.9)$ & $42(21.1)$ & $140(20.8)$ & \\
\hline Haemorrhage* & $69(6.9)$ & $12(5.1)$ & $57(7.5)$ & .21 \\
\hline Place of birth & & & & .01 \\
\hline Home & $58(5.7)$ & $6(2.5)$ & $52(6.7)$ & \\
\hline Birth centre & $215(22.2)$ & $41(17.2)$ & $163(21)$ & \\
\hline Hospital & $742(73.1)$ & $192(80.3)$ & $561(72.3)$ & \\
\hline $\begin{array}{l}\text { Transfer during } \\
\text { labour* }\end{array}$ & 275 (28.6) & $60(26.4)$ & $215(29.3)$ & .41 \\
\hline $\begin{array}{l}\text { Induction of } \\
\text { labour* }\end{array}$ & $313(30.9)$ & $100(42)$ & $213(27.4)$ & .00 \\
\hline $\begin{array}{l}\text { Medical pain } \\
\text { relief* }\end{array}$ & $415(41)$ & $124(52.1)$ & $291(37.6)$ & .00 \\
\hline $\begin{array}{l}\text { Gestational } \\
\text { age at onset } \\
\text { of labour in } \\
\text { weeks mean (sd) }\end{array}$ & $39(2.4)$ & $38.7(2.3)$ & $39(2.5)$ & .22 \\
\hline $\begin{array}{l}\text { Duration of } \\
\text { dilatation in } \\
\text { hours median } \\
\text { (IQR) }\end{array}$ & $6.0(.8)$ & $6.0(.9)$ & $6.0(.8)$ & .09 \\
\hline $\begin{array}{l}\text { Duration of } \\
\text { expulsion in } \\
\text { minutes median } \\
\text { (IQR) }\end{array}$ & $16.0(1.6)$ & $14.9(1.7)$ & $16.0(1.6)$ & .81 \\
\hline
\end{tabular}

in midwifery-led care. It utilised high-quality data from a medical database and had a negligible amount of missingness. Since the database included complete medical and background information, it was possible to accurately identify the number of consultations and to examine its relationship with perinatal outcomes. The cohort was described previously [23] and is representative for pregnant women seen in primary midwifery care in the Netherlands, except for the almost twice as high 
Table 5 Perinatal outcomes of frequent attenders and non-frequent split by referral $(N=1015)$

\begin{tabular}{|c|c|c|c|c|c|c|}
\hline & $\begin{array}{l}\text { Non-referred } \\
\text { frequent attender } \\
N=107(10.5 \%)\end{array}$ & $\begin{array}{l}\text { Non-referred } \\
\text { non-frequent } \\
\text { attender } \\
\mathrm{N}=431 \text { (42.5\%) }\end{array}$ & $\begin{array}{l}P \\
\text { value }\end{array}$ & $\begin{array}{l}\text { Referred } \\
\text { frequent attender } \\
N=132(13.0 \%)\end{array}$ & $\begin{array}{l}\text { Referred } \\
\text { non-frequent } \\
\text { attender N = } 345 \\
(34.0 \%)\end{array}$ & $P$ value \\
\hline Apgar Score after $5 \mathrm{~min}^{*}$ & & & .19 & & & .27 \\
\hline$<8$ & $5(4.7)$ & $10(2.3)$ & & $2(1.5)$ & $12(3.5)$ & \\
\hline Perinatal death & $1(0.9)$ & $4(0.9)$ & 1 & $0(0.0)$ & $6(1.7)$ & .13 \\
\hline Birthweight (in percentiles)* & & & .13 & & & .79 \\
\hline$P<10$ & $6(5.7)$ & $45(10.5)$ & & $13(9.9)$ & 37 (10.9) & \\
\hline Mode of delivery * & & & .76 & & & .34 \\
\hline Spontaneous & $87(82.1)$ & $366(85.1)$ & & $87(65.9)$ & $224(65.1)$ & \\
\hline Vaginal assisted birth & $13(12.3)$ & $43(10.0)$ & & $9(6.8)$ & $38(11.0)$ & \\
\hline Caesarean section & $6(5.7)$ & $21(4.9)$ & & $36(27.3)$ & $82(23.8)$ & \\
\hline Perineum* & & & .26 & & & .03 \\
\hline Not ruptured & $50(49.0)$ & $216(52.9)$ & & $59(60.8)$ & $117(44.2)$ & \\
\hline Ruptured & $28(27.5)$ & $125(30.6)$ & & $20(20.6)$ & $75(28.3)$ & \\
\hline Episiotomy & $24(23.5)$ & $67(16.4)$ & & $18(18.6)$ & $73(27.5)$ & \\
\hline Haemorrhage* & $5(4.7)$ & $22(5.2)$ & .84 & $7(5.4)$ & $35(10.4)$ & .10 \\
\hline Place of birth & & & .01 & & & .34 \\
\hline Home & $5(4.7)$ & $52(12.1)$ & & $1(0.8)$ & $0(0.0)$ & \\
\hline Birth centre & $37(36.4)$ & $156(36.2)$ & & $7(5.3)$ & $14(4.1)$ & \\
\hline Hospital & $63(58.9)$ & $223(51.7)$ & & $124(93.9)$ & $331(95.9)$ & \\
\hline Transfer during labour* & $60(56.1)$ & $210(48.7)$ & .21 & NA & NA & \\
\hline Induction of labour* & NA & NA & & $96(73.3)$ & $205(59.4)$ & .02 \\
\hline Medical pain relief* & $45(42.1)$ & $112(26.0)$ & .01 & $79(60.3)$ & $179(52.0)$ & .40 \\
\hline $\begin{array}{l}\text { Gestational age at onset of } \\
\text { labour in weeks mean }(\mathrm{sd})\end{array}$ & $38.9(2.6)$ & $39.3(2.1)$ & .05 & 38.6 (1.9) & $38.7(2.8)$ & .67 \\
\hline $\begin{array}{l}\text { Duration of dilatation in } \\
\text { hours median (IQR) }\end{array}$ & $8.0(5.0-11.0)$ & $6.0(4.0-9.0)$ & $<.01$ & $6.0(4.0-9.0)$ & $6.0(4.0-9.0)$ & .48 \\
\hline $\begin{array}{l}\text { Duration of expulsion in } \\
\text { minutes median (IQR) }\end{array}$ & $17.0(8.8-39.0)$ & $15.0(7.0-37.0)$ & .40 & $14.0(7.0-32.0)$ & $17.0(8.0-33.0)$ & .18 \\
\hline
\end{tabular}

*sample size varies due to missing data; valid percentages are shown

**SD = standard deviation; IQR = interquartile range

prevalence of non-Dutch women allowing to study differences by ethnicity [23, 41].

The main limitation of this exploratory study is the relatively small study population $(n=1015)$, that means that relatively rare outcomes such as suboptimal Apgar score and perintal death could not be assessed. As this study included only one midwifery practice, generalisation to all pregnant women should be made with caution. Another limitation is that the reasons for induction of labour and C-section were unknown.

\section{Comparison with literature}

The literature lacks studies concerning non-referred and referred FAs in prenatal healthcare, making it difficult to directly compare our result with others. Our study showed that FA in the non-referred group was associated with medical pain relief. One possible explanation might be the higher rates of sexual violence among nonreferred FAs compared to non-referred non-FAs (16\% vs 9\%) as sexual violence is associated with higher rates of general or lifetime anxiety [42, 43]; there is a significantly higher demand for pain relief among women who were anxious during pregnancy [44, 45]. Furthermore, non-referred FAs in our study had a significantly longer primary stage of labour, and pain relief might prolong delivery [46].

In the Dutch maternity care system, if a low-risk pregnant woman has a request for induction of labour, she will be referred to an obstetrician. In line with a large cohort study in obstetric care, FAs in the referred group in our study had more often an induction of labour [27]. The higher rates of induction could be explained by gestational stress, one of the underlying reasons for FA [23]. In this context, gestational stress means that the 
Table 6 Unadjusted and adjusted associations between frequent attendance/non-frequent attendance and perinatal outcomes, stratified by referral

\begin{tabular}{|c|c|c|c|c|}
\hline & \multicolumn{2}{|l|}{ Non-referred } & \multicolumn{2}{|l|}{ Referred } \\
\hline & $\begin{array}{l}\text { Unadjusted } \\
\mathrm{n} \leq 538^{*}\end{array}$ & $\begin{array}{l}\text { Adjusted } \\
\mathrm{n} \leq 538^{*}\end{array}$ & $\begin{array}{l}\text { Unadjusted } \\
\mathrm{n} \leq 477^{*}\end{array}$ & $\begin{array}{l}\text { Adjusted } \\
n \leq 477^{*}\end{array}$ \\
\hline & OR $(95 \% \mathrm{Cl})$ & OR $(95 \% \mathrm{Cl})$ & OR $(95 \% \mathrm{Cl})$ & OR $(95 \% \mathrm{Cl})$ \\
\hline \multicolumn{5}{|l|}{ Mode of delivery* } \\
\hline \multicolumn{5}{|l|}{ Spontaneous } \\
\hline Assisted birth\# & $1.25(0.71-2.19)$ & $1.14(0.63-2.07)$ & $0.97(0.64-1.47)$ & $0.94(0.60-1.47)$ \\
\hline \multicolumn{5}{|l|}{ Birthweight (in percentiles)* } \\
\hline \multicolumn{5}{|l|}{$p \geq 10$} \\
\hline$p>10$ & $0.51(0.21-1.24)$ & $0.51(0.21-1.24)$ & $0.90(0.46-1.76)$ & $0.93(0.47-1.84)$ \\
\hline \multicolumn{5}{|l|}{ Perineum* } \\
\hline \multicolumn{5}{|l|}{ Not ruptured } \\
\hline Ruptured & $0.97(0.58-1.62)$ & $1.05(0.61-1.80)$ & $0.53(0.30-0.95)$ & $0.50(0.27-0.95)$ \\
\hline Episiotomy & $1.55(0.89-2.71)$ & $1.53(0.80-2.94)$ & $0.49(0.27-0.89)$ & $0.48(0.24-0.95)$ \\
\hline \multicolumn{5}{|l|}{ Haemorrhage* } \\
\hline \multicolumn{5}{|l|}{ No } \\
\hline Yes & $0.91(0.34-2.47)$ & $0.97(0.37-2.78)$ & $0.50(0.21-1.15)$ & $0.52(0.22-1.21)$ \\
\hline \multicolumn{5}{|l|}{$\begin{array}{l}\text { Place of birth } \\
\text { Home/birth centre }\end{array}$} \\
\hline Hospital & $1.34(0.87-2.05)$ & $1.36(0.87-2.12)$ & NA & NA \\
\hline \multicolumn{5}{|l|}{ Transfer during labour* } \\
\hline \multicolumn{5}{|l|}{ No } \\
\hline Yes & $1.34(0.87-2.06)$ & $1.31(0.85-2.03)$ & NA & NA \\
\hline \multicolumn{5}{|l|}{ Induction of labour* } \\
\hline \multicolumn{5}{|l|}{ No } \\
\hline Yes & NA & NA & $1.87(1.20-2.92)$ & $1.86(1.17-2.95)$ \\
\hline \multicolumn{5}{|l|}{ Medical pain relief* } \\
\hline \multicolumn{5}{|l|}{ No } \\
\hline Yes & $2.06(1.34-3.20)$ & $1.98(1.24-3.17)$ & $1.40(0.93-2.11)$ & $1.38(0.88-2.15)$ \\
\hline Log duration of dilatations in hours & $1.20(1.04-1.38)$ & $1.20(1.04-1.38)$ & $1.03(0.87-1.21)$ & $1.03(0.87-1.21)$ \\
\hline Log duration of expulsion in minutes & $1.06(0.83-1.36)$ & $1.06(0.83-1.36)$ & $0.91(0.70-1.20)$ & $0.91(0.70-1.20)$ \\
\hline
\end{tabular}

*sample size varies due to missing data; ${ }^{*}$ vaginal assisted birth and Caesarean section together; OR $=$ odds ratio, $\mathrm{Cl}=$ confidence intervals $95 \%$ No regression analysis for:

Apgar score

Perinatal death

Gestational age

level of stress experienced by the pregnant woman is higher than she can cope with [47].

Over the last years, studies have examined the exposure to episiotomies in midwifery-led care and obstetric-led care settings and demonstrated that women in which labour was induced and who received regional analgesia have significantly higher rates of episiotomy [48, 49]. Our study showed higher rates of induced labour and demand for medical pain relief among referred FAs. However, contrary to earlier results, we found a significant lower episiotomy rate and ruptured perineum. The associations between the provision of pain relief, ruptured perineum and episiotomy need to be examined in general but also in FA.

Contrary to other research, we did not find an association between FA and C-section or vaginal assisted birth $[27,35]$. The discrepancy may be explained by different factors. One important factor could be differences in cut-off points to categorise FA. Carter et al. used a cutoff point of more than 10 prenatal visits $(>10)$ to define FA, based on the median of the study population, instead of using the Kotelchuck-Index [50]. Moreover, the 10 prenatal visits were lower than the 12 prenatal visits 
recommended by the ACOG for women who started prenatal care in the first trimester [51]. Additionally, Carter et al. used a different control group than our study: all pregnant women with 10 or less prenatal visits (adequate and inadequate together), whereas our control group existed only of women with the adequate (and recommended) number of prenatal visits. Different interpretations of FA highlights the need for an internationally accepted and established definition of FA to be able to compare studies, establish relevant risk factors, and inform clinical guidelines.

\section{Future research}

Our study was exploratory, and therefore it is recommended to repeat our study in a larger setting to improve the external validity of the results. Furthermore, this would allow to study relatively rare perinatal outcomes, e.g. suboptimal Apgar score and perinatal death, and result in more robust conclusions on the relationship between FA and obstetric and neonatal outcomes. We advise future studies to include the moment (gestational age) at which women are referred to an obstetrician in the analyses. Also, research about the underlying mechanisms of FA has to be performed, targeted explicitly on provider-related factors and client-related factors which could contribute to overuse of prenatal

\section{Conclusion}

Perinatal outcomes differed by perinatal healthcare utilisation and antenatal referral to an obstetrician. Nonreferred FAs had relatively more often medical pain relief and longer duration of dilatation, whereas referred FAs had relatively more often an induction of labour. Further research within a larger study population is needed to assess possible associations between FA and rare adverse birth outcomes such as perinatal death and low Apgar score. FA influences the perinatal health care system; further research is needed on how professionals and management should organise prenatal care for FAs to improve care; research should also focus on the experiences and needs of FAs.

\section{Supplementary information}

Supplementary information accompanies this paper at https://doi.org/10. 1186/s12884-020-02957-1.

\section{Additional file 1}

\section{Abbreviations}

FA: Frequent Attendance; Non-FA: Non-frequent Attendance; KNOV: Koninklijke Organisatie van Verloskundigen - the Royal Dutch Organisation of Midwives; KI-R: The Kotelchuck Index-Revised

\section{Authors contributions}

JG and LM designed the study with the support of EF. JG collected the data. $J G$ and LG, and PS conducted the statistical analyses independently and discussed the slight differences in outcomes. JG, LG, PS en AH discussed the interpretations. JG drafted the manuscript with the advice and input of all authors; all authors corrected draft versions of the manuscript and approved the final manuscript.

\section{Funding}

The study has been funded by the Royal Dutch Organization of Midwives (KNOV) Fellowship 2017. The KNOV had no involvement of the funders in the study design, data analyses, manuscript preparation, and publication decisions [22].

\section{Availability of data and materials}

The datasets used and analysed during the current study are available from the corresponding author on reasonable request.

\section{Ethics approval and consent to participate}

On the 25th of January 2018, the Medical Ethics Committee of the VU University Medical Center (ref. 2018.019) approved this study to collect and analyse retrospective data of January 2015 to January 2017. Women permitted to use their anonymous data, their verbal consent was obtained during the intake and noted in their files while they watched; the beforementioned Medical Ethics Committee approved this procedure of obtaining consent [22].

\section{Consent for publication}

No details on individuals have been reported within the manuscript. As described above, participants permitted to use their anonymous data; consent for publication is not applicable.

\section{Competing interests}

The work of Dr. Janneke Gitsels-van der Wal was funded by KNOV Fellowship 2017. The work of the other authors was not funded, and they have nothing to disclose [22]

\section{Author details}

${ }^{1}$ Amsterdam UMC, Vrije Universiteit Amsterdam, Midwifery Science, AVAG, Amsterdam Public Health research institute, Van der Boechorststraat 7, 1081 HV Amsterdam, The Netherlands. ${ }^{2}$ ESRC funded Business and Local Government Data Research Centre (BLG DRC), School of Computing Sciences, University of East Anglia, Norwich Research Park, Norwich NR4 7TJ, UK. ${ }^{3}$ University College London, London, UK. ${ }^{4}$ Department of Obstetrics and Gynaecology, Amsterdam UMC, Vrije Universiteit Amsterdam, De Boelelaan, 1117 Amsterdam, Netherlands. ${ }^{5}$ Zaans Medical Center, Department of Obstetrics and Gynecology, Koningin Julianaplein 58, Zaandam, Netherlands. ${ }^{6}$ Department of General Practice \& Elderly Medicine, University of Groningen, University Medical Center Groningen, POBox 30001, 9700, RB, Groningen, the Netherlands.

Received: 9 December 2019 Accepted: 20 April 2020

Published online: 06 May 2020

References

1. Gill D, Sharpe M. Frequent consulters in general practice: A systematic review of studies of prevalence, associations and outcome. Vol. 47, Journal of Psychosomatic Research. 1999. p. 115-30.

2. Smits FT, Brouwer HJ, Zwinderman AH, Mohrs J, Schene AH, van Weert HCPM, et al. Why do they keep coming back? Psychosocial etiology of persistence of frequent attendance in primary care: a prospective cohort study. J Psychosom Res. 2014;77(6):492-503.

3. Pasgaard AA, Mæhlisen MH, Overgaard C, Ejlskov C, Torp-Pedersen C, Bøggild $\mathrm{H}$. Social capital and frequent attenders in general practice: a register-based cohort study. BMC Public Health. 2018;18(310).

4. Smits FT, Brouwer HJ, Ter Riet G, Van Weert HCP. Epidemiology of frequent attenders: a 3-year historic cohort study comparing attendance, morbidity and prescriptions of one-year and persistent frequent attenders. BMC Public Health. 2009;9.

5. Morriss R, Kai J, Atha C, Avery A, Bayes S, Franklin M, et al. Persistent frequent attenders in primary care: costs, reasons for attendance, 
organisation of care and potential for cognitive behavioural therapeutic intervention. BMC Fam Pract. 2012;13.

6. Naessens JM, Baird MA, Van Houten HK, Vanness DJ, Campbell CR. Predicting persistently high primary care use. Ann Fam Med. 2005;3(4):324-30.

7. Malins S, Kai J, Atha C, Avery A, Guo B, James M, et al. Cognitive behaviour therapy for long-term frequent attenders in primary care: A feasibility case series and treatment development study. Br J Gen Pract [Internet]. 2016; 66(651):e729-36. Available from: http://www.embase.com/search/ results?subaction=viewrecord\&from=export\&id=L612621751\%0Ahttp://dx. doi.org/10.3399/bjgp16X686569\%0Ahttp://resolver.ebscohost.com/ openurl?sid=EMBASE\&issn=09601643\&id=doi:10.3399\%2Fbjgp16X68656 9\&atitle=Cognitive+behaviour+therap.

8. Smits FTM, Wittkampf KA, Schene AH, Bindels PJE, Van Weert HCPM Interventions on frequent attenders in primary care. Scand J Prim Health Care [Internet]. 2008;26(2):111-6 Available from: http://www.tandfonline. com/doi/full/10.1080/02813430802112997.

9. Cooper LG, Leland NL, Alexander G. Effect of maternal age on birth outcomes among young adolescents. Soc Biol. 1995;42(1-2):22-35.

10. Zozzaro-Smith PE, Bacak S, Conway C, Park J, Glantz JC, Thornburg LL, Association between obesity during pregnancy and the adequacy of prenatal care. Matern Child Health J. 2015;20(1):158-63.

11. Luo ZC, Wilkins R, Kramer MS. Effect of neighbourhood income and maternal education on birth outcomes: a population-based study. CMAJ. 2006;174(10):1415-20.

12. Urquia ML, Glazier RH, Blondel B, Zeitlin J, Gissler M, Macfarlane A, et al. International migration and adverse birth outcomes: Role of ethnicity, region of origin and destination. Vol. 64, Journal of Epidemiology and Community Health. 2010. p. 243-51.

13. Ong KK, Diderholm B, Salzano G, Wingate D, Hughes IA, MacDougall J, et al. Pregnancy insulin, glucose, and BMI contribute to birth outcomes in nondiabetic mothers. Diabetes Care. 2008;31(11):2193-7.

14. Inoue $\mathrm{S}$, Naruse H, Yorifuji T, Kato T, Murakoshi T, Doi H, et al. Impact of maternal and paternal smoking on birth outcomes. J public health (Oxf) [internet]. 2016;fdw050. Available from. http://www.ncbinlm.nih.gov/ pubmed/27222236.

15. Lisonkova S, Janssen PA, Sheps SB, Lee SK, Dahlgren L. The effect of maternal age on adverse birth outcomes: does parity matter? J Obstet Gynaecol Canada. 2010;32(6):541-8.

16. Jyväsjärvi S, Joukamaa $M$, Väisänen E, Larivaara P, Kivelä S, KeinänenKiukaanniemi S. Somatizing frequent attenders in primary health care. J Psychosom Res. 2001;50(4):185-92.

17. Haroun D, Smits F, van Etten-Jamaludin F, Schene A, van Weert $H$, ter Riet $G$. The effects of interventions on quality of life, morbidity and consultation frequency in frequent attenders in primary care: A systematic review. Vol. 22, European Journal of General Practice. 2016. p. 71-82.

18. Ickovics JR, Earnshaw V, Lewis JB, Kershaw TS, Magriples U, Stasko E, et al. Cluster randomized controlled trial of group prenatal care: perinatal outcomes among adolescents in New York city health centers. Am J Public Health. 2016;106(2):359-65.

19. Feijen-de Jong El, Jansen DEMC, Baarveld F, Boerleider AW, Spelten E, Schellevis $F$, et al. Determinants of prenatal health care utilisation by lowrisk women: a prospective cohort study. Women and Birth [Internet]. 2015; 28:87-94 Available from: http://linkinghub.elsevier.com/retrieve/pii/S187151 9215000074 .

20. De Boer, J., Zeeman, K. Prenatale verloskundige begeleiding. Aanbevelingen voor ondersteuning, interactie en voorlichting. KNOV-standaard Wetenschappelijke onderbouwing, 2008 Utrecht. In Dutch. Available from: https://www.knov.nl/serve/file/knov.nl/knov_downloads/985/file/ Wetenschappelijke\%20onderbouwing\%20standaard\%20prenatale\%2 Overloskundige\%20begeleiding.pdf.

21. Yeoh PL, Hornetz K, Dahlui M. Antenatal care utilisation and content between low-risk and high-risk pregnant women. PLoS One. 2016;11(3).

22. Ny P, Dykes AK, Molin J, Dejin-Karlsson E. Utilisation of antenatal care by country of birth in a multi-ethnic population: a four-year community-based study in Malm?? Sweden Acta Obstet Gynecol Scand. 2007;86(7):805-13.

23. Gitsels - van der Wal JT, Gitsels LA, Hooker A, Weert B van, Martin L, Feijen - de Jong El. Determinants and underlying causes of frequent attendance in midwife-led care: an exploratory cross-sectional study. BMC Pregn Childbirth 2019 19:203.

24. Alderliesten ME, Vrijkotte TGM, Van Der Wal MF, Bonsel GJ. Late start of antenatal care among ethnic minorities in a large cohort of pregnant women. BJOG An Int J Obstet Gynaecol. 2007;114(10):1232-9.
25. Organization world health. WHO Recommendation on Antenatal care for positive pregnancy experience. WHO Recomm Antenatal care Posit pregnancy Exp [Internet]. 2016;152. Available from: http://apps.who.int/iris/ bitstream/10665/250796/1/9789241549912-eng.pdf.

26. NICE guidelines committee. NICE Guideline: Intrapartum care for healthy women and babies. [Internet]. NICE (National Institute for Health and Care Excellence). 2014. p. 1-58. Available from: https://www.nice.org.uk/ guidance/cg55.

27. Carter EB, Tuuli MG, Caughey AB, Odibo AO, Macones GA, Cahill AG. Number of prenatal visits and pregnancy outcomes in low-risk women. J Perinatol. 2016;36(3):178-81.

28. Farbu J, Haugen M, Meltzer HM, Brantsæter AL. Impact of singlehood during pregnancy on dietary intake and birth outcomes- A study in the Norwegian Mother and Child Cohort Study. BMC Pregnancy Childbirth. 2014;14(1).

29. Jackson RA, Gibson KA, Wu YW, Croughan MS. Perinatal outcomes in singletons following in vitro fertilization: A meta-analysis. Vol. 103, Obstetrics and Gynecology. 2004. p. 551-63.

30. Murray SR, Norman JE. Multiple pregnancies following assisted reproductive technologies - A happy consequence or double trouble? Vol. 19, Seminars in Fetal and Neonatal Medicine. 2014. p. 222-7.

31. Storgaard M, Loft A, Bergh C, Wennerholm UB, Söderström-Anttila V, Romundstad LB, et al. Obstetric and neonatal complications in pregnancies conceived after oocyte donation - a systematic review and meta-analysis. BJOG [internet]. 2016;1-12. Available from. http://www.ncbi.nlm.nih.gov/ pubmed/27592694.

32. Hill A, Pallitto C, McCleary-Sills J, Garcia-Moreno C. A systematic review and meta-analysis of intimate partner violence during pregnancy and selected birth outcomes. Vol. 133, International Journal of Gynecology and Obstetrics. 2016. p. 269-76.

33. Boerleider AW, Mannien J. Stenus CMV van, Wiegers TA, Feijen - de Jong El, Spelten ER. Devillé WLJM Explanatory factors for first and second-generation non-western women's inadequate prenatal care utilisation: a prospective cohort study BMC Pregn Childbirth. 2015;15:98.

34. Raatikainen $\mathrm{K}$, Heiskanen $\mathrm{N}$, Heinonen $\mathrm{S}$. Under-attending free antenatal care is associated with adverse pregnancy outcomes. BMC Public Health. 2007;7:268.

35. De Jonge A, Rijnders M, Agyemang C, Van Der Stouwe R, Den Otter J, Van Den Muijsenbergh METC, et al. Limited midwifery care for undocumented women in the Netherlands. J Psychosom Obstet Gynecol. 2011;32(4):182-8.

36. Carter EB, Tuuli MG, Odibo AO, Macones GA, Cahill AG. Prenatal visit utilization and outcomes in pregnant women with type II and gestational diabetes. J Perinatol. 2017;37(2):122-6.

37. Kotelchuck M. An evaluation of the Kessner adequacy of prenatal care index and a proposed adequacy of prenatal care utilization index. Am J Public Health. 1994;84(9):1414-2038.

38. Postal codes table: https://www.lhv.nl/uw-beroep/aanbod/bijzonderepatientengroepen/patienten-achterstandswijken.

39. World Health Organisation - BMI. Available from: http://www.euro.who.int/ en/health-topics/disease-prevention/nutrition/a-healthy-lifestyle/body-massindex-bmi.

40. Vannieuwenborg L, Buntinx F, De Lepeleire J. Presenting prevalence and management of psychosocial problems in primary care in Flanders. Arch Public Health. 2015;73(1):10.

41. Perined. Perinatal Care in the Netherlands 2016. In Dutch, available from: https://assets.perined.nl/docs/7935f9c6-eaac-4f59-a150-307ae04efa27.pdf.

42. Chen LP, Murad MH, Paras ML, Colbenson KM, Sattler AL, Goranson EN, et al. Sexual abuse and lifetime diagnosis of psychiatric disorders: systematic review and meta-analysis. Mayo Clin Proc [Internet]. 2010;85(7):618-29 Available from: http://inkinghub.elsevier.com/retrieve/pii/S0025619611601663.

43. Leeners B, Rath W, Block E, Görres G, Tschudin S. Risk factors for unfavorable pregnancy outcome in women with adverse childhood experiences. J Perinat Med. 2014;42(2):171-8.

44. Koelewijn JM, Sluijs AM, Vrijkotte TGM. Possible relationship between general and pregnancy-related anxiety during the first half of pregnancy and the birth process: A prospective cohort study. BMJ Open. 2017;7(5).

45. Sitras V, Saltyte Benth J, Eberhard-Gran M. Obstetric and psychological characteristics of women choosing epidural analgesia during labour: a cohort study. PLoS One. 2017;12(10):e0186564.

46. Aweda A, Rutahoile W, Jackson P, Liao B, Zhou X. The Outcome Analysis of Epidural Analgesia on Labor in Primigravid Women: A Systematic Review and Meta-Analysis Focusing on Duration of Labor. J Pain Manag Med. 2016;2(3). 
47. González-Ochoa R, Sánchez-Rodríguez EN, Chavarría A, Gutiérrez-Ospina G, Romo-González T. Evaluating stress during pregnancy: do we have the right conceptions and the correct tools to assess it? J Pregnancy. 2018;4857065.

48. Shmueli A, Gabbay Benziv R, Hiersch L, Ashwal E, Aviram R, Yogev Y, et al. Episiotomy-risk factors and outcomes*. J Matern Neonatal Med. 2017;30(3): 251-6.

49. Cromi A, Bonzini M, Uccella S, Serati M, Bogani G, Pozzo N, et al. Provider contribution to an episiotomy risk model. J Matern Neonatal Med. 2015; 28(18):2201-6.

50. Buekens P, Kotelchuck M, Blondel B, Kristensen FB, Chen JH, MasuyStroobant G. A comparison of prenatal care use in the United States and Europe. Am J Public Health. 1993 Jan;83(1):31-6.

51. American Academy of Pediatrics ACoO, Gynecologists. Perinatal Care Clinical Practice Guidelines 2012 Available from: http:/passporthealthplan. com/wp-content/uploads/2016/07/HLTH62565-updated-Perinatal-CPG.pdf.

\section{Publisher's Note}

Springer Nature remains neutral with regard to jurisdictional claims in published maps and institutional affiliations.

Ready to submit your research? Choose BMC and benefit from:

- fast, convenient online submission

- thorough peer review by experienced researchers in your field

- rapid publication on acceptance

- support for research data, including large and complex data types

- gold Open Access which fosters wider collaboration and increased citations

- maximum visibility for your research: over $100 \mathrm{M}$ website views per year

At $B M C$, research is always in progress.

Learn more biomedcentral.com/submissions 